\title{
O valor da biodiversidade e o impasse taxonômico: a diversidade marinha como estudo de caso
}

\section{The value of biodiversity and the taxonomical impasse: marine diversity as a case study}

\author{
Paulo da Cunha LANA*
}

\section{RESUMO}

A diversidade biológica vem deixando de ser tratada como conceito ecológico estrito nos últimos anos e assumindo as características de um verdadeiro recurso global, graças aos avanços da biologia molecular e da engenharia genética. Apesar disto, não existem ainda boas estimativas da biodiversidade nem mesmo como grandeza taxonômica. Um caso particularmente evidente deste desconhecimento generalizado é dado pela própria biodiversidade marinha. Cerca de 200 mil espécies de plantas e animais marinhos são atualmente conhecidas, mas há estimativas, mais ou menos fundamentadas, de que a diversidade potencial possa variar de $500 \mathrm{mil}$ a 5 milhões de espécies. Este artigo tem por objetivo avaliar criticamente o conceito de biodiversidade, com ênfase no caso particular da biodiversidade marinha, juntamente com uma análise da atual disponibilidade de recursos humanos e materiais para o seu simples levantamento taxonômico.

Palavras-chave: biodiversidade, diversidade marinha, impasse taxonômico.

\section{ABSTRACT}

Rather than an ecological concept, biological diversity is more and more evaluated as a real global resource, due to the advances of molecular biology and genetic engineering. However, not even taxonomical biodiversity is adequately known, as shown by the case of marine environments. About 200000 species of marine plants and animals are currently known, but estimates ranging from 500000 to 5 million species have been put forward. This paper critically assesses the concept of biodiversity, using marine diversity as a case study. Current needs of human and material resources to survey the variability of life in the oceans are appraised and discussed.

Key-words: biodiversity, marine diversity, taxonomic expertise. 


\section{Introdução}

A diversidade é uma propriedade inerente ao mundo que nos rodeia e aos sistemas biológicos e ecológicos em particular. A diversidade biológica ou biodiversidade é um conceito genérico e relativamente vago, aplicável aos mais diversos níveis de organização biológica e usado para qualificar ou quantificar de alguma maneira a rica variabilidade da vida na Terra. Mais objetivamente, pode ser considerada como a soma de toda a variabilidade biológica desde o nível dos genes até os ecossistemas (PURVIS; HECTOR, 2000). Em sua acepção mais simples e mais facilmente compreensível pela maioria das pessoas, é vista como o número de espécies de animais, vegetais ou microorganismos que vivem em uma região ou habitat em um dado momento.

A Avaliação da Biodiversidade Global (ABG), conduzida por 1.500 cientistas em meados da década de 1990, com o apoio do United Nations Environment Programme - UNEP, sumarizou e atualizou o conhecimento (ou desconhecimento) até então disponível sobre a diversidade biológica no nível dos ecossistemas, espécies e genomas. Adotando uma margem de incerteza com uma ordem de grandeza, a ABG estimou a existência de 13 milhões de espécies na biosfera, das quais apenas $13 \%$ cientificamente descritas (HEYWOOD, 1995).

Independente das incertezas quanto ao tamanho da biodiversidade global, existe hoje uma clara percepção de que as atividades humanas, com sua crescente demanda sobre as espécies e seus habitats, têm contribuído para um aumento das taxas de extinção globais e para colocar em risco esse patrimônio natural (CHAPIN, 2000). Apesar do reconhecimento generalizado dessa imensa riqueza ecológica e das suas implicações socioeconômicas, os correntes sistemas de mercado ainda engatinham nas tentativas de valoração econômica da biodiversidade ou das funções ou serviços prestados pelos ecossistemas em escala terrestre (COSTANZA et al., 1997; VIVIEN, 2000).

Um dos requisitos óbvios para a correta avaliação da diversidade biológica é que os taxonomistas, ou seja, os cientistas que descrevem e nomeiam as espécies, possam conduzir levantamentos da fauna e da flora em ambientes terrestres e marinhos. Para isto, esses taxonomistas devem ter à sua disposição os recursos materiais para cumprir essa tarefa. Esta situação desperta um natural questionamento: os recursos humanos e materiais ora disponibilizados em escala global são suficientes ou adequados para atender esta demanda? E mais ainda, a sociedade pode e deve arcar com os custos inerentes a levantamentos desta natureza?

$\mathrm{Na}$ tentativa de abordar estas questões, este artigo tem por objetivo avaliar criticamente o conceito de biodiversidade, com ênfase no caso particular da biodiversidade marinha, apresentar algumas evidências atuais de quão grande ela é (ou do tamanho que possa atingir), além de discutir a pertinência e adequação dos maciços investimentos de recursos humanos e materiais necessários para seu levantamento e quantificação.

\section{A biodiversidade: conceito biológico ou metáfora conservacionista?}

A literatura sobre a diversidade biológica é extraordinariamente extensa, variando desde abordagens descritivas e experimentais até complexos estudos de modelagem ecológica (HUSTON, 1994; ORMOND et al., 1997). Valores de diversidade, medidos por uma infinidade de índices mais ou menos complexos (KREBS, 1999), são quase sempre expressos como números que sintetizam ou comprimem uma quantidade de informações contidas em uma associação. Tais valores numéricos não têm, por si só, maior valor e sua confiabilidade como expressão da organização ou estrutura de comunidades tem sido fortemente questionada (GRAY, 1981). Um valor numérico isolado, oferecido como expressão da diversidade de uma comunidade, é menos informativo do que a simples lista de espécies que de fato o gerou.

Por outro lado, índices de diversidade podem adquirir relevância biológica quando relacionados com outros atributos da comunidade. Por exemplo, pode ser interessante medir a diversidade de uma comunidade para eventualmente relacioná-la com a sua estabilidade e produtividade ou com as condições ambientais prevalecentes. Uma aplicação prática, por vezes bem-sucedida, é a correlação de valores de diversidade com processos de poluição (GRAY, 1981). Existe a noção intuitiva, freqüentemente confirmada por estudos de campo, de que a diversidade animal e vegetal tende a diminuir em áreas poluídas. Neste caso, índices de diversidade poderiam ser utilizados como ferramentas biológicas para avaliar o grau de perturbação ou modificação de um determinado ambiente por atividades humanas. 
A idéia de que comunidades ou ecossistemas mais diversificados seriam mais estáveis (e vice-versa) encontrou enorme ressonância na literatura ecológica e no próprio movimento conservacionista (GOODMAN, 1975). Esta hipótese se fundamentou em uma série de presumíveis evidências empíricas, como experimentos de laboratório (por exemplo, a constatação de que sistemas predador-presa simples, com um predador e uma presa, tendem à extinção). Da mesma forma, a idéia parecia validada por observações de que as monoculturas são mais sensíveis às pragas do que as policulturas ou associações vegetais "naturais", de que comunidades menos diversificadas de ilhas são muito vulneráveis a invasões e de que as faunas polares, de baixa diversidade, parecem muito mais variáveis ao longo do tempo do que as faunas tropicais, que seriam mais estáveis.

No entanto, a natureza da relação entre a estabilidade e a diversidade de sistemas biológicos permanece obscura para as ciências naturais (PURVIS; HECTOR, 2000; TILMAN, 2000) e a base empírica para validar um ou outro modelo explicativo permanece inadequada (GOODMAN, 1975; Mc CANN, 2000).

A hipótese de que a diversidade está relacionada com a estabilidade dos sistemas biológicos pode ser vista alternativamente como uma metáfora poderosa, que exerce uma atração de natureza estética, acentuando a presumida unicidade da natureza e sua presumível sensibilidade a pequenas alterações. Esta idéia é um prato cheio, por exemplo, para aqueles que acreditam que variações na densidade de uma única espécie, por menos abundante que seja, possam ter enormes repercussões sobre as associações de que fazem parte ou sobre os ecossistemas em que vivem. Por isto mesmo, a idéia continua sendo tão influente no movimento conservacionista.

\section{O tamanho da diversidade biológica $e$ a importância das espécies individuais}

A diversidade biológica vem deixando de ser tratada como conceito ecológico estrito nos últimos anos e assumindo as características de um verdadeiro recurso global, graças aos avanços da biologia molecular e da engenharia genética. Apesar disto, não temos ainda nem mesmo boas estimativas da diversidade biológica vista como simples grandeza taxonômica. Existem hoje descri- tas mais de 1,5 milhão espécies animais e vegetais, das quais metade são insetos. São muitas as especulações em torno do número de espécies de plantas, animais e microorganismos ainda não descritas e Wilson (1988) as estimou entre 5 e 30 milhões. A estimativa mais confiável no momento permanece a da Avaliação Global da Diversidade (HEYWOOD, 1995), com 13 milhões de espécies atuais. Todos estes números são fortemente especulativos, mas fundamentados pela percepção relativamente recente da enorme diversidade dos animais em florestas tropicais e grandes planícies abissais.

O conceito de diversidade biológica, quando tratado no nível das associações ou comunidades, traz em si uma outra questão crucial: será que todas as espécies são igualmente importantes em um sistema? O conceito de importância é muito relativo, mas existe uma tendência generalizada de se considerar "importantes" aquelas espécies que se destacam por sua abundância ou por serem mais evidentes ou aparentes na natureza. $O$ fato é que a importância ecológica ou funcional de uma espécie em uma comunidade nem sempre é função de sua simples abundância ou dominância numérica. São igualmente importantes aquelas espécies com uma grande capacidade de afetar a diversidade e abundância das demais, sem necessariamente serem as mais abundantes. Essas espécies-chave ou reguladoras podem tanto ocupar níveis tróficos inferiores (no caso dos produtores primários) ou superiores (predadores de predadores). Sua ação tende a regular, por meio de um verdadeiro "efeito cascata" para baixo ou para cima, as densidades de outras populações e as próprias configurações espaciais e temporais das comunidades em que vivem (RICKLEFS, 2003).

Portanto, os conceitos de importância e dominância não devem ser considerados sinônimos. Espécies numericamente dominantes são aquelas reconhecidas por sua abundância numérica ou por sua biomassa, embora nem sempre responsáveis pela estruturação da comunidade a que pertencem. Por outro lado, os conceitos de dominância e diversidade específica estão estreitamente relacionados, já que comunidades dominadas por poucas espécies tendem a exibir menores valores de diversidade.

Estas considerações levam à conclusão de que os levantamentos taxonômicos, se não exaustivos, deveriam pelo menos procurar apreender aquela porção da diversidade biológica representada pelas espécies-chave e 
pelas espécies numericamente dominantes, além daquelas que são, por si mesmas, recursos de interesse imediato para o homem, sob a forma de alimentos, fármacos etc.

\section{O caso especial da biodiversidade marinha}

A maioria dos filos animais marinhos quase certamente evoluiu nos oceanos primitivos e muitos deles estão inteiramente restritos à água salgada. É bastante provável que os ambientes marinhos tenham sido colonizados em um estágio muito inicial da história evolutiva, o que explicaria a elevada diversidade animal ali encontrada. Por outro lado, embora nem todos os grupos animais tenham conseguido colonizar os meios terrestres, aqueles que o conseguiram foram extremamente bem-sucedidos e se diversificaram em milhões de espécies. Isto foi provavelmente uma consequiência da elevada variabilidade ou heterogeneidade espacial dos continentes, fator que favoreceria o isolamento reprodutivo e a formação de novas espécies (SUMMERHAYES et al., 1996).

Os insetos são o grupo terrestre com maior sucesso evolutivo, mas em compensação possuem poucos representantes marinhos. Excluídos os insetos, aproximadamente $65 \%$ das espécies animais atuais são marinhas. Ao contrário dos ambientes terrestres, os oceanos são habitats relativamente uniformes e de certa forma caracterizados pela ausência de grandes barreiras geográficas, que poderiam ser um instrumento de especiação. Isto ajuda a explicar porque apenas $2 \%$ das espécies marinhas pertencem ao chamado sistema pelágico, em oposição às restantes, que vivem ou estão associadas ao fundo do mar, constituindo o chamado sistema bêntico ou bentônico. O elevado número de espécies bênticas, em comparação com as pelágicas, sugere que as características geográficas ou texturais dos substratos marinhos podem fornecer oportunidades de especiação não registradas nas massas d'água sobrejacentes, que tendem a ser mais contínuas e uniformes (SUMMERHAYES et al., 1996).

O que se sabe hoje da biodiversidade marinha? Ela é elevada, ultrapassando 200 mil espécies, das quais 3 mil pelágicas e o resto bênticas, com amplo predomínio da macrofauna, que inclui moluscos, crustáceos e poliquetas. Da mesma forma, não deve ser subestimada a diversidade potencial dos organismos meiofaunais, que vivem no espaço entre os grãos do sedimento, como nematódios e copépodes e cujo estudo ainda pode ser considerado incipiente. A diversidade biológica marinha tende a aumentar com o crescente conhecimento de habitats marinhos mais profundos, como as planícies abissais onde certamente existem centenas de milhares ou milhões de espécies ainda não descritas (ORMOND et al., 1997). A diversidade desses habitats foi subestimada até 30 anos atrás, basicamente por causa das naturais dificuldades de amostragem. Projeções e extrapolações feitas a partir de levantamentos faunais realizados em regiões do talude continental e das planícies abissais sugerem que o número real de espécies macrofaunais bênticas possa variar de 500 mil a 5 milhões (SNELGROVE, 1998). Apesar disto, o estudo dessa riqueza biológica apenas começou. Não é exagero dizer que existem hoje nas prateleiras dos museus e nas coleções departamentais ou particulares de instituições de ensino e pesquisa milhares de espécies por serem descritas. Mesmo a diversidade animal de águas rasas não deixa de ser surpreendente (GRAY, 2002), particularmente quando os levantamentos são conduzidos por grupos de taxonomistas especialistas, trabalhando em conjunto.

\section{Quantas espécies é preciso conhecer para se compreender o funcionamento de uma comunidade ou ecossistema?}

Esta questão foi exemplarmente abordada por Scheltema (1996), que comparou a estrutura de duas associações bênticas muito distintas, contrapondo a diversidade de uma baía de águas rasas, ao largo da costa leste norte-americana, com a diversidade de fundos abissais, em latitude equivalente. Amostras provenientes de 19 metros de profundidade em Buzzard's Bay (Massachussetts), totalizando cerca de $2 \mathrm{~m}^{2}$ de área total, continham 79 espécies macrofaunais, ou seja, animais retidos por peneiras com mais de $0,5 \mathrm{~mm}$ de malha. No entanto, $75 \%$ da associação era dominada por uma espécie de bivalve (Nucula proxima) e uma de poliqueta (Nephtys incisa). As 7 espécies mais abundantes perfaziam $91 \%$ do total de indivíduos coletados, ou seja, as 72 espécies remanescentes compreendiam $9 \%$ da fauna. Estes valores foram comparados com aqueles observados em amostras tomadas em fundos abissais, a $2.000 \mathrm{~m}$. 
Nesta situação, 798 espécies foram coletadas, ou seja, 10 vezes mais do que o número de espécies da baía rasa. A espécie mais abundante, um poliqueta, representava apenas $7 \%$ do total de indivíduos. As duas espécies mais abundantes representavam apenas $12 \%$ do total. As 7 espécies mais abundantes representam apenas $28 \%$ do total.

Que conclusão pode ser tirada dessa análise comparativa? Para estimar ou "apreender" a diversidade da fauna de águas profundas, seria necessário identificar muito mais espécies do que na baía de águas mais rasas, como base inicial para se saber como é que a comunidade se estrutura e funciona. De fato, muitas espécies muito raras ou ocasionais podem não exercer maior influência sobre a comunidade, embora isto nem seja sempre uma regra biológica ou ecológica. Em resumo: quantas espécies devem ser descritas? No mar profundo, onde a diversidade é caracteristicamente alta, praticamente todas deveriam ser descritas, já que não há muitas espécies dominantes. Por outro lado, nos fundos de águas rasas, a descrição de umas poucas espécies já forneceria um elevado grau de compreensão da associação como um todo, ou seja, mais uma vez, não há uma resposta simples ou única (SCHELTEMA, 1996).

\section{O impasse taxonômico e a necessidade de conhecimento da biodiversidade: perspectivas de médio e longo prazo}

Toda a enorme variabilidade biológica, ainda não inteiramente mapeada e nem mesmo estimada, desperta perguntas importantes. É realmente necessário nomear e descrever todas ou cada uma das espécies existentes para compreender ou estimar a diversidade biológica de uma fauna particular e da biosfera como um todo? Vale a pena empreender esta tarefa, considerando a extensão dos recursos humanos e materiais que serão necessários?

Esta não é uma pergunta que deva ser respondida pelos cientistas, mas pela sociedade como um todo. Em todo caso, os taxonomistas deveriam ser capazes de adiantar algumas indicações úteis para ajudar a sociedade a tomar estas decisões. Não é particularmente difícil responder à primeira parte da pergunta. É possível avançar muito no conhecimento de um ecossistema por meio da análise do fluxo de matéria e energia entre seus compartimentos, sem necessariamente discriminar ou nomear todas as espécies ali existentes. Por causa disto, muitos especialistas, como os analistas de ecossistemas e os biogeoquímicos, tendem a subestimar a importância da correta discriminação das espécies animais e vegetais. No entanto, é possível perceber rapidamente que essas interações e fluxos são de fato modulados pela própria biodiversidade, o que exigirá, mais cedo ou mais tarde, o conhecimento preciso e não ambíguo das espécies presentes. Neste contexto, as estimativas da biodiversidade não são apenas um valor em si, mas frequientemente tornam-se necessárias para que melhores descrições e previsões dos ecossistemas possam ser feitas, de forma a garantir a sua exploração mais racional.

A Agenda de Pesquisas da Academia Nacional de Ciências dos Estados Unidos, de 1995, afirma no seu item sobre diversidade que

...o nível de investigação da biodiversidade deve ser definido pelas questões científicas e pela urgência das ameaças ambientais percebidas...

Esta concepção, apesar de vaga e genérica, é ainda a melhor diretriz para guiar estudos relacionados com o levantamento da biodiversidade, de forma a racionalizar o investimento de recursos humanos e materiais.

Como estimar a biodiversidade de uma maneira mais racional e otimizada em um quadro de restrições humanas e materiais? A taxonomia é uma ciência descritiva relativamente precisa e isto se tornou particularmente verdadeiro com a progressiva incorporação das abordagens filogenéticas, ocorridas nas duas ou três últimas décadas. Por um triste paradoxo, justamente quando se torna uma ciência mais precisa e por isto mesmo mais atraente, tanto o interesse como as oportunidades de treinamento taxonômico vêm caindo drasticamente nos últimos 50 anos, em escala global. Esta tendência não resulta apenas da falta de verbas e recursos materiais. A própria comunidade científica tem uma enorme culpa histórica neste processo por ter, em algum momento de um passado não muito distante, desestimulado sistematicamente as vocações potenciais dos jovens biólogos, vendendo (ou praticando) uma imagem da taxonomia como um conjunto de procedimentos estéreis e enfadonhos. $O$ resultado foi perceptível, com uma perda progressiva de interesse das novas gerações por essa ciência, acompanhada de uma sensível redução da capacitação 
taxonômica, que é ainda mais evidente nos países mais desenvolvidos. Para muitos grupos animais, há poucos especialistas ativos e para alguns, não há quaisquer especialistas atuantes. A identificação específica confiável de muitos grupos bênticos marinhos é quase impossível, simplesmente porque não há taxonomistas capacitados ou competentes, face às dimensões desta tarefa global (SCHELTEMA, 1996; GIBBS et al., 1999).

Mesmo nos países em desenvolvimento, algumas das principais razões deste estado de coisas não são primariamente materiais, mas antes de escassez, inadequação ou distribuição desigual de recursos humanos (HAJDU et al., 1998; MIGOTTO; MARQUES, 2003). A situação é crítica tanto nos países considerados desenvolvidos como naqueles em desenvolvimento. No caso brasileiro, por exemplo, podemos reconhecer a existência de uma massa crítica atuante em diversas áreas das ciências marinhas, mesmo nas regiões mais carentes. É insatisfatória, apesar disto, a massa crítica treinada e institucionalmente estabelecida em universidades, museus ou centros de pesquisa para lidar taxonomicamente com a diversidade biológica dos ambientes marinhos. Pior do que isto, continuam praticamente ausentes os mecanismos para forçar uma efetiva interação desses pesquisadores, como forma de acelerar o desenvolvimento da capacitação regional.

A carência de recursos materiais é importante, principalmente no contexto regional, embora tenda a ser superestimada pela própria comunidade científica, na medida em que trabalhos taxonômicos de qualidade podem ser feitos com poucos recursos. Tão danosa quanto essa falta de recursos para a pesquisa taxonômica ou para a montagem de laboratórios bem equipados é a ausência de museus ou coleções de referência das faunas regionais ou do financiamento para sua implantação e manutenção. Para remediar a situação, o crônico problema de inadequação das bibliotecas tem sido parcialmente solucionado nos últimos anos, graças à facilidade de acesso à informação bibliográfica proporcionada pela tecnologia da informação e pela Internet, disponível mesmo nos centros menos desenvolvidos.

Em diversos países do mundo, iniciativas tímidas foram tomadas para reverter esta situação. Nos Estados Unidos, foi criado o programa Parcerias para Aumentar a Atividade Taxonômica, da National Science Foundation (PEET, em <www.nsf.gov/pubs/2000/nsf00140/ nsf00140.htm $>$ ), com a finalidade de apoiar pesquisas com grupos animais pouco conhecidos e de treinar uma nova geração de taxonomistas. Outra importante iniciativa não-governamental é o Expert Center for Taxonomic Identification (ETI, em <www.eti.uva.nl/>), apoiado pela Unesco, que tem entre seus objetivos a melhoria do acesso geral e a promoção de um uso mais amplo do conhecimento mundial sobre a biodiversidade. No que se refere especificamente à biodiversidade marinha, deve ser mencionado o programa de pesquisas internacional Census of Marine Life (CoML, em <www.coml.org $>$ ), que procura avaliar e explicar alterações na diversidade, abundância e distribuição da vida nos oceanos (O' DOR, 2003).

No Brasil, uma das únicas iniciativas recentes que tratam sistematicamente da fauna bêntica marinha é o Programa Biota, financiado pela Fapesp, em São Paulo, por meio do seu projeto de levantamento da biodiversidade bêntica marinha do estado de São Paulo (detalhes em <www.biota.org.br/projeto/ index?show+191>), limitado ao litoral norte daquele estado. Várias iniciativas do próprio Ministério do Meio Ambiente, dos Recursos Hídricos e da Amazônia Legal, como o Programa Nacional da Diversidade Biológica (Pronabio), não têm escopo ou vertentes propriamente taxonômicas. Embora muito se fale atualmente em biodiversidade, pouco se investe em levantamentos taxonômicos abrangentes e sistematizados. Como resultado, os taxonomistas marinhos brasileiros têm de se contentar com o material gerado por suas coletas esparsas e fragmentadas, geralmente limitadas a áreas costeiras rasas. Mais raramente, torna-se disponível o material resultante de amplos programas institucionais, governamentais ou não, como é o caso do Programa de Levantamento dos Recursos Vivos da Zona Econômica Exclusiva (Revizee) ou dos trabalhos de avaliação de impactos ambientais, principalmente conduzidos pela Petrobras. Como tais programas foram planejados e desenvolvidos para fins aplicados, muitas vezes o material zoológico obtido não sofre o tratamento ou processamento adequados para objetivos taxonômicos. Diagnósticos mais detalhados dos impasses e descompassos taxonômicos no país foram apresentados por Hajdu et al. (1998) e Migotto; Marques (2003).

Como resolver estes problemas? A curto e médio prazo, é preciso lidar com a escassez e a desigualdade na distribuição dos recursos humanos e das competências taxonômicas especializadas. É essencial, neste caso, a intensificação da educação geral em ciências marinhas 
em todos os níveis da sociedade, desde o ensino fundamental até a pós-graduação, com a devida valorização das formações taxonômicas. A médio e longo prazo, uma alternativa para lidar com a questão da desigualdade na distribuição de recursos seria a otimização da massa crítica já existente, ainda que incipiente, por meio da criação de redes de pesquisa. Essas redes deveriam promover um comportamento cooperativo e não competitivo, colocando em contato e interação direta não apenas os recursos humanos, mas também as facilidades de laboratórios, bancos de dados, centros de modelagem, instrumentos, barcos etc. Um dos mecanismos possíveis para viabilizar essas redes seria a criação de verdadeiras oficinas taxonômicas que congregassem taxonomistas bem qualificados, por tempos determinados, nas regiões mais carentes do país. Essas oficinas promoveriam o treinamento de jovens cientis-

\section{REFERENCIAS}

COSTANZA, R. et al. The value of the world's ecosystem services and natural capital. Nature, n. 387, p. 253-269, 1997.

CHAPIN, F. S. et al. Consequences of changing biodiversity. Nature, n. 405, p. 234-242, 2000.

GIBBS, M. et al. The taxonomic richness of South Africa's marine fauna: a crisis at hand. South African Journal of Science, n. 95, p. 8-12, 1999.

GOODMAN, D. The theory of diversity-stability relationships in ecology. The Quarterly Review of Biology, $\mathrm{v}$. 50, n. 3, p. 237-266, 1975.

GRAY, J. S. The ecology of marine sediments. Cambridge: Cambridge University Press, 1981. $185 \mathrm{p}$.

GRAY, J. S. Species richness of marine soft sediments. Marine Ecology Progress Series, n. 244, p. 285-297, 2002.

HAJDU, E. M., GIANUCA, N. M.; AMARAL, A. C. Z. O impedimento taxonômico e a crise da biodiversidade. In: SIMPÓSIO DE ECOSSISTEMAS BRASILEIROS, 4., Águas de Lindóia. Anais... São Paulo: Academia de Ciências do Estado de São Paulo, 1998. p. 227-245.

HEYWOOD, V. H. (Ed.). Global Biodiversity Assessment. United Nations Environment Programme. Cambridge: Cambridge University Press, 1995.

HUSTON, M. A. Biological diversity. The coexistence of species on changing landscapes. Cambridge: Cambridge University Press, 1994. 681 p. tas e pesquisadores locais, paralelamente ao trabalho intensivo de identificação da biodiversidade regional.

As necessidades de levantamento da biodiversidade deveriam ser claramente dimensionadas e qualificadas, antes de sua eventual incorporação às políticas científicas, como meras palavras de ordem. Deveriam ser consubstanciadas em programas de pesquisa viáveis e desejáveis. Em vez de seduzida, pelos próprios cientistas, a aceitar os estudos da biodiversidade como um fim em si, a sociedade deveria ser corretamente informada dos custos materiais e humanos potencialmente associados a este monumental empreendimento. Estes seriam requisitos mínimos para uma adequada definição de prioridades que levassem em conta não só as urgências ambientais, mas também as próprias questões científicas com repercussão socioeconômica.

KREBS, C. J. Ecological methodology. 2. ed. Menlo Park: Addison Wesley Longman, 1999. 620 p.

McCANN, K. S. The diversity-stability debate. Nature, n. 405, p. 228-233, 2000.

MIGOTTO, A. E.; MARQUES, A. C. Avaliação do estado do conhecimento da diversidade de invertebrados marinhos no Brasil. In: SIMPÓSIO DE BIOLOGIA MARINHA, 18., 2003, São Sebastião. Disponível em: <http://www.usp.br/ cbm/novo_site/simposio/simp_xviii/resumos/ palestra_008.html>.

O'DOR, R. K. The unknown ocean. The baseline report of the Census of Marine Life Research Program. Washington DC: Consortium for Oceanographic Research and Education, $2003.28 \mathrm{p}$.

ORMOND, R. F. G.; GAGE, J. D.; ANGEL, M. V. Marine biodiversity: patterns and processes. Cambridge: Cambridge University Press, 1997. 449 p.

PURVIS, A.; HECTOR, A. Getting the measure of biodiversity. Nature, n. 405, p. 212-219, 2000.

RICKLEFS, R. E. A economia da natureza. 5. ed. Rio de Janeiro: Guanabara Koogan, 2003. 503 p.

SCHELTEMA, R. Describing diversity. Too many species, too few taxonomists. Oceanus, v. 39, n. 1, p. 16-18, 1996.

SNELGROVE, P. V. R. The biodiversity of macrofaunal organisms in marine sediments. Biodiversity and Conservation, n. 7, p. 1123-1132, 1998. 
LANA, P. da C. O valor da biodiversidade e o impasse...

SUMMERHAYES, C. P.; THORPE, S. A.; KITCHING, VIVIEN, F. D. Quel prix accorder à labiodiversité? La Recherche, J. A. Oceanography - An illustrated guide. London: $\quad$ n. 333, p. 88-91, 2000.

Manson Publishing Ltd., 1996.

TILMAN, D. Causes, consequences and ethics of biodiversity. Nature, n. 405, p. 208-211, 2000.

WILSON, E. O. The diversity of life. New York: W. W. Norton \& Company, 1992. 